\title{
AS SEMENTES E O CONHECIMENTO QUE ELAS INCORPORAM
}

\author{
Hugh Lacey \\ Professor de Filosofia no Swarthmore College (Pensilvânia, EUA) e no momento Professor visitante na USP. \\ Tem atuado como Professor visitante na USP, Unicamp e PUC-SP
}

\begin{abstract}
Resumo: Freqüentemente recorre-se à ciência para legitimar a prioridade atribuída ao desenvolvimento de sementes transgênicas na pesquisa agronômica, e a proteção privilegiada concedida aos direitos de propriedade intelectual sobre tais sementes. Alega-se que as sementes transgênicas incorporam conhecimento científico, mas não as sementes selecionadas na agricultura tradicional; e que o conhecimento científico sustenta não haver, além da agricultura que faz uso substancial de sementes transgênicas, maneira alternativa nenhuma de alimentar a humanidade. Ambas as alegações são questionadas por meio de um argumento que reconhece na agroecologia uma séria alternativa (pelo menos parcialmente) à predominância da biotecnologia na agricultura, uma alternativa que não apenas encontra forte apoio na evidência empírica, mas também responde aos valores da sustentabilidade ecológica e da justiça social.

Palavras-chave: desenvolvimento científico; transgênicos; agroecologia.
\end{abstract}

$\mathrm{N}$ a consciência moderna avultam as conquistas e promessas da ciência, assim como os ampliados poderes humanos de exercer controle resultantes dos desenvolvimentos científicos. Embora a ciência e as novas tecnologias provoquem medo e apreensão em algumas pessoas, para a maioria no mundo contemporâneo seu valor foi profundamente internalizado. Assim, uma ampla legitimidade foi atribuída à pesquisa e aos desenvolvimentos de novas possibilidades tecnológicas, e há uma tendência a aceitar como pressuposto - não sem oposição - que o futuro será, e mesmo deverá ser, em grande parte moldado em resposta a eles. As sementes transgênicas (TG) e outros "avanços" biotecnológicos estão entre os mais recentes e mais visíveis de tais desenvolvimentos.

Para seus defensores as sementes TG representam o futuro da agricultura; elas são também testemunho do engenho e providência do empreendimento científico. Um manual muito usado tem por título Tecnologia do DNA: a espantosa habilidade (Alcamo, 1996), um bom resumo da situação. Criticar a biotecnologia parece beirar a blasfêmia, uma oposição ao desdobrar do futuro e à própria ciência. Busca-se com freqüência a legitimação do desenvolvimento e emprego de sementes TG na autoridade e prestígio da ciência e com isto espera-se silenciar todos os críticos. Contrariando essa postura, pode-se argumentar que a ciência não autoriza tal legitimação, e não coloca barreiras à exploração de formas alternativas de agri- cultura que estejam mais em sintonia com a luta por justiça social.

As sementes TG contêm genes tirados de organismos de diferentes espécies, inseridos diretamente em seus próprios materiais genéticos, com a finalidade de gerar plantas com as específicas qualidades "desejadas", tais como as capacidades de resistir a inseticidas. Para seus criadores, as sementes TG incorporam conhecimento científico e trazem a marca da ciência. Elas também trazem a marca da economia política da "globalização", uma vez que seu desenvolvimento tem sido visto tanto como um objetivo da economia neoliberal global quanto como um meio de fortalecer suas estruturas. Tais marcas gêmeas emprestam uma aura de inevitabilidade à "revolução" agrícola prometida com o advento das sementes TG: a ciência definiu a rota, a economia global fornece as estruturas para sua efetiva implementação. Assim, não é surpresa que as plantações com sementes TG (milho, soja, e outras culturas) tenham tido um crescimento explosivo nos últimos anos. Não há outro caminho, os defensores insistem, nenhuma outra maneira de fornecer o necessário para alimentar a crescente população mundial nas próximas décadas. ${ }^{1}$ Devem os críticos silenciar?

Os críticos são de vários tipos. Alguns rejeitam cabalmente ou mostram-se apreensivos diante da "intrusão na natureza” exemplificada pelas sementes TG (Príncipe de Gales, 1998). Outros exigem medidas de precaução à luz 
dos riscos ambientais e para a saúde, da inadequação dos procedimentos de avaliação de riscos, de questões de escolha dos consumidores e rotulagem de produtos TG, de ameaças à biodiversidade, perigos de controle do suprimento de alimentos pelas grandes empresas, e o solapamento potencial das condições necessárias para a agricultura orgânica (Risler e Mellon, 1996; Lappé e Bailey, 1998). Alguns criticam o uso corrente de sementes TG por visar principalmente o lucro empresarial, embora apoiem a pesquisa e desenvolvimento que tem por objetivo ajudar os povos dos países empobrecidos, por exemplo, produzindo arroz mais rico em vitamina (Nuffield Council on Biothics, 1999; Serageldin, 1999). Alguns pensam que os riscos envolvidos são motivo para que se abandone todo o empreendimento. Ainda outros questionam o projeto de globalização e estão envolvidos tanto na pesquisa quanto na luta política para tornar viáveis métodos alternativos de agricultura (Altieri e Rosset, 2000; Kloppenburg, 1991; Shiva, 1993).

São poucas as concessões dos defensores. Eles reconhecem riscos, naturalmente, mas sustentam que os riscos reais podem ser administrados e regulamentados. Com o apoio da US Food and Drug Administration, eles também alegam não haver evidência científica concreta de que produtos $\mathrm{TG}$ atualmente no mercado causem riscos maiores que os produtos da agricultura convencional. Confiantes nos resultados e promessas da ciência, e encorajados por seus sucessos anteriores, eles não se deixam abalar por apelos para que se tenha especial cautela no uso de produtos TG. Além disso, não concedem aos críticos a posição de superioridade moral. Bem ao contrário, replicam que o uso de sementes TG permite alta produtividade combinada com uma atitude amigável em relação ao meio ambiente, e, como já mencionado, insistem que é necessário alimentar a humanidade (Specter, 2000). Dessa perspectiva quaisquer riscos ocasionados pelo uso de sementes TG desaparecem na insignificância em comparação com as conseqüências de sua não-utilização; é aos críticos que falta a devida preocupação moral (McGloughlin, 2000).

Muita coisa depende da alegação de que "não há outra maneira" de alimentar a humanidade. A legitimidade de ir adiante rápida e imediatamente com o emprego de sementes TG, sem tomar medidas de precaução especiais, pressupõe sua veracidade. Será que ela é realmente verdadeira? Se não, quais são as alternativas? É apoiada por evidências científicas? Ou é apenas um reflexo de quem está seguramente dominado pela atitude moderna perante a ciência, com sua fé nela e na tecnologia avançada para resolver todos os problemas? Ou, talvez, seja o código para "esta é a maneira de proceder dentro das estruturas da globalização", cuja progressiva consolidação é considerada inevitável e não deixa nada de fora (Lacey, 1998, cap. 8), e para um reconhecimento oculto de que estas estruturas, por meio de mecanismos como a concessão seletiva de direitos de propriedade intelectual (DPI), tendem a solapar as alternativas (Lewontin, 1998)?

As sementes TG não podem ser produzidas sem a modificação de sementes selecionadas pelos agricultores (sementes SA), ou sementes derivadas originalmente de sementes SA, para uso na agricultura convencional. Sua própria existência pressupõe o desenvolvimento anterior destas últimas (Kloppenburg, 1988). E contudo as proteções dos DPI podem ser concedidas a sementes TG mas não a sementes SA. Na falta de tais proteções, as sementes SA são consideradas parte do patrimônio comum da humanidade e podem ser (sob os predominantes acordos internacionais e leis em vigor) legalmente apropriadas à vontade sem consulta ou compensação aos agricultores que as selecionaram (Kloppenburg, 1987). Quando as sementes SA são apropriadas, os críticos falam de "biopirataria" e detectam injustiça. Os que desenvolvem as sementes TG apropriam-se livremente das sementes SA, mas o agricultor não tem livre acesso a sementes TG. Não apenas o agribusiness (por seus pesquisadores), mas também gerações de agricultores contribuem para a produção de sementes TG mas, graças aos DPIs, quem lucra são principalmente o agribusiness e seus clientes. Quaisquer lucros desse tipo pressupõem a livre apropriação das sementes SA. Mais ainda, as condições em que acontecem tendem a facilitar a substituição das sementes SA pelas $\mathrm{TG}^{2}{ }^{2} \mathrm{~A}$ biopirataria envolve não apenas a exploração dos agricultores que produzem as sementes, sem as quais as sementes TG não poderiam existir, mas também, no final, a exclusão do próprio uso destas sementes (Shiva, 1997; 2000). A biopirataria e o regime dos DPIs são profundamente interligados. O desenvolvimento e a utilização das sementes TG dependem de ambos.

Quais diferenças entre sementes TG e SA podem justificar a norma de que àquelas, mas não a estas, sejam concedidas as proteções dos DPIs? Uma das diferenças apontadas consiste em que as sementes TG mas não as SA incorporam conhecimento cientifico. Em virtude disso elas podem satisfazer os critérios padrão para conseguir uma patente - novidade, inventividade, utilidade/aplicação industrial, e fornecimento de instruções suficientes para 
estar de acordo com a condição de "suficiência de revelação" - e assim tornar-se propriedade intelectual. Dessa perspectiva é pura demagogia e sentimentalismo chamar de biopirataria a livre apropriação e possível substituição de sementes SA. O prestígio da ciência é dessa forma mobilizado contra o uso de um termo moralmente tão carregado. Apenas a propriedade pode ser pirateada, e as sementes SA não são propriedade intelectual. Além disso, de acordo com seus defensores, o desenvolvimento de sementes TG beneficia a todos, pois "não há outro meio de alimentar a humanidade."

Será verdade que, primeiro, as sementes TG mas não as $\mathrm{SA}$ incorporam conhecimento científico; e segundo, que as sementes SA não podem formar a base (ou uma parte importante) da produção necessária para alimentar a humanidade? Respostas afirmativas às duas questões constituiriam um grande avanço na direção de legitimar não apenas a transformação da agricultura para acomodar as sementes TG, mas também a "biopirataria" e a privilegiada proteção concedida às sementes TG pelos DPIs.

Ao tratar dessas questões, estará em jogo a pergunta "em que consiste a ciência?" Considera-se que a ciência inclui qualquer forma sistemática e empírica de investigação que procura entender os fenômenos do mundo, ou seja, que almeja captar as causas e possibilidades das coisas e fenômenos (Lacey, 1998; 1999, cap. 5). Que formas de investigação científica devem ser empreendidas se desejamos estudar sistemática e empiricamente as possibilidades de alimentar a humanidade no futuro, e testar a alegação de que culturas TG são necessárias e amplamente suficientes, e culturas SA insuficientes (e nem mesmo necessárias em certas localidades), para este fim (Lacey, $\mathrm{s} / \mathrm{d})$ ? Tenha-se em mente a persistência da fome hoje; e que produzir alimento suficiente para alimentar a todos não significa que todos serão alimentados. Sermos todos alimentados depende não apenas da produção de alimento em quantidade suficiente, mas também que as pessoas tenham acesso a ele; $\mathrm{e}$, para pessoas não-participantes de comunidades agrícolas produtivas, isso significa ter de comprá-lo (Altieri e Rosset, 2000). Deve-se observar também que a manutenção de alta produtividade a longo prazo depende da preservação da biodiversidade, da saúde humana e ambiental, e da ausência de conflitos sociais violentos (Altieri, 1995). Lembrando tudo isso, pode-se ficar cético quanto à idéia de que as culturas TG vão permitir que a humanidade seja alimentada. Afinal, elas estão inseridas na mesmas estruturas e representam os mesmos interesses que aceitaram a persistência da fome e da desnutrição apesar de haver produção suficiente para alimentar a todos.

Com certeza não há nada na maneira como a ciência biotecnológica é conduzida hoje que possa refrear o ceticismo, pois ela se ocupa primordialmente com a estrutura molecular dos genes, a química de suas expressões, e de como elas podem ser modificadas para produzir traços "desejados" nas plantas, sem dar atenção ao impacto ecológico a longo prazo das culturas (Risler e Mellon, 1996) e (na medida em que é custeada pelo agribusiness) praticamente nenhuma ao impacto social geral. Porém, sem uma investigação sistemática e empírica sobre os impactos ecológico e social a longo prazo, e sobre a possibilidade de alternativas, como poderia a pesquisa científica apoiar a tese de que o desenvolvimento de sementes TG é o único modo de proceder, ou mesmo que é um modo viável de proceder? Naturalmente, essa questão teria pouca relevância se de fato não houvesse alternativas.

A fim de se ter claro o que está envolvido, devem ser consideradas mais duas questões:

- maximização: como podemos maximizar a produção de uma cultura em condições - uso de fertilizantes, controle de pragas, emprego de água, maquinário, linhagens de sementes, etc. - que podem ser amplamente replicadas?

- fortalecimento local: como podemos produzir culturas de modo que todas as pessoas na região de produção tenham acesso a uma dieta bem equilibrada num contexto que fortaleça a ação e o bem-estar locais, sustenha a biodiversidade, preserve o ambiente e favoreça a justiça social?

Ambas são questões científicas; ambas estão abertas à investigação de maneiras empíricas e sistemáticas. São questões diferentes, relacionadas a preocupações morais e sociais diferentes. A primeira enfatiza as quantidades de alimento produzidas, a segunda, quem de fato é alimentado e em que condições. Responder a uma delas, e adotar os métodos necessários para respondê-la, não é suficiente para responder à outra.

Os métodos biológicos utilizados para investigar o que pode ser produzido com sementes TG são apropriados para a maximização. Tais métodos tentam identificar possibilidades do ponto de vista da capacidade de serem geradas as sementes a partir de estruturas moleculares subjacentes e processos bioquímicos regidos por leis. Eles abstraem em grande parte a realização de tais possibilidades e suas relações com arranjos sociais, vidas e experiências humanas, as condições sociais e materiais da pesquisa, e o impacto ecológico amplo e de longo prazo - e desta forma, 
de qualquer ligação com valores. São métodos "materialistas", métodos que separam a biologia da sociologia, da economia e da ecologia, de tal forma que ofortalecimento local não é considerado como pertencendo propriamente ao mesmo domínio de pesquisa que a maximização. Quando não simplesmente ignorado, é discutido nas ciências sociais, depois de terem sido respondidas questões como a da maximização.

Existem, entretanto, outras abordagens para a investigação científica, cujos resultados podem informar práticas agrícolas alternativas, especificamente aquelas da agroecologia. A pesquisa em agroecologia - embora recorrendo de inúmeras maneiras ao conhecimento das estruturas subjacentes e da química das plantas, solos e insumos da produção agrícola - situa a agricultura integralmente dentro de sua situação ecológica e social, e coloca questões que não envolvem abstrações dela (Altieri, 1995). De acordo com Altieri, um de seus mais notáveis proponentes, ${ }^{3}$ ela trata as coisas em relação ao agroecossistema (sistema agrícola/ecológico) inteiro de que são partes constituintes, e preocupa-se simultaneamente com: "[A] manutenção da capacidade produtiva do agroecossistema, a preservação da base de recursos naturais e da biodiversidade, o fortalecimento da organização social e diminuição da pobreza, [e] o fortalecimento [empowerment] das comunidades locais, manutenção das tradições, e participação popular no processo de desenvolvimento" (Altieri, 1998:56-7). Ela não separa a biologia da sociologia por qualquer razão de princípio. Seu foco primordial são as questões do tipo do fortalecimento local; e assim seus resultados variam com a localidade, recorre e desenvolve (em muitos casos) o conhecimento tradicional que informa as práticas de uma cultura, e não restringe os papéis na geração do conhecimento a especialistas, preservando papéis para os próprios agricultores (Lacey, 1998, cap. 6). As sementes SA incorporam variedades de conhecimento agroecológico (Shiva, 1991).

Uma vez que o fortalecimento local situa-se fora da perspectiva daqueles que restringem a investigação ao uso de métodos materialistas, sua pesquisa não pode nos dizer que as alternativas agrícolas informadas por pesquisa agroecológica são incapazes de fornecer uma parte importante da base necessária para alimentar a humanidade. Dessa forma, quando eles alegam que "não há outra maneira", não estão relatando um resultado de sua pesquisa científica, ou mesmo uma hipótese que eles tenham os meios para investigar seriamente. Aparentemente a alegação decorre ou da aceitação acrítica das promessas da ciência praticada com métodos materialistas, ou do interesse dos agentes e projetos da economia global.

Os defensores das sementes TG não se deixarão abalar por esse argumento. Como muitos outros que adotam a postura moderna perante a ciência, eles tendem a identificála com o emprego praticamente exclusivo dos métodos materialistas. Num nível, trata-se apenas de uma questão terminológica. A palavra "ciência" é, na verdade, amplamente utilizada para designar "pesquisa empírica sistemática praticada com métodos materialistas", o tipo de investigação que leva à expansão de nossa capacidade de exercer controle sobre os objetos naturais. Não tenho objeção alguma a esse nível. Tudo o que foi dito pode ser reformulado sem perdas usando "pesquisa empírica sistemática" em vez de "ciência" (Lacey, 1999, cap. 5).

Num outro nível, entretanto, sustenta-se que a terminologia usual reflete o fato de o conhecimento adquirido com métodos materialistas ser (em princípio) mais solidamente assentado em evidências empíricas e experimentais, e que ele tem credenciais epistêmicas superiores. Isso se questiona. A pesquisa agroecológica parte de conhecimento adequadamente testado na prática em culturas tradicionais, por exemplo, o conhecimento incorporado em sementes SA, que forneceu a "matéria-prima" para o desenvolvimento de sementes TG. O fato desse conhecimento carecer da "universalidade" do conhecimento materialista e (com freqüência) de sua forma teórica precisamente integrada não significa que ele seja empiricamente menos bem-assentado, mas é um tipo de conhecimento bastante específico quanto ao local, e capaz de fornecer respostas a questões como a do fortalecimento local. Restringir o uso de "ciência" na pesquisa praticada com métodos materialistas representa assim a concessão de um privilégio para a pesquisa materialista - porém um privilégio não conquistado em bases epistêmicas (Kloppenburg, 1991; Shiva, 1991).

Conceder privilégio ao conhecimento científico adquirido com métodos materialistas desvia a atenção para longe de formas alternativas de agricultura, informadas por conhecimento científico (sistemático e empírico), que em princípio pode levar a respostas positivas e eficazes para a questão do fortalecimento local em muitas localidades, e pode até gerar produtividade local aumentada, consistente com a sustentabilidade ecológica e social, a partir de melhoramentos nos métodos segundo os mais as sementes SA são coletadas (Lewontin e Berlan, 1990). Também insinua que temos apenas opinião, não conhecimento sólido, quando lidamos com a completa e temporalmente 
extensa série de variáveis ecológicas, humanas e sociais e os efeitos das práticas agrícolas. Assim, ele solapa ilegitimamente a força da crítica baseada na investigação agroecológica. Por outro lado, os métodos materialistas são de maneira geral adequados para tratar da maximização, e realmente levam à identificação de possibilidades genuínas das culturas TG. Não podem, porém, identificar as possibilidades necessárias para tratar do fortalecimento local, e é impossível responder à grande questão da necessidade de desenvolvimento de sementes TG se nos abstivermos de utilizar métodos que levem em conta esse fortalecimento. A grande questão pode ser tratada cientificamente, por meio de investigação empírica sistemática, mas apenas se permitirmos que a ciência inclua uma variedade de métodos, dos quais o materialista é apenas um (embora muito importante). Métodos de investigação materialistas e agroecológicos estão em princípio no mesmo patamar. Outros autores, influenciados pelo construcionismo social, tiraram conclusões semelhantes questionando a "objetividade" do conhecimento materialista bem-estabelecido; nossas conclusões apontam a "objetividade" do conhecimento agroecológico.

Tanto as sementes SA quanto as TG podem ser informadas pelo conhecimento científico: umas pelo conhecimento agroecológico, outras pelo conhecimento materialista. Assim, a concessão de proteções dos DPIs às sementes TG mas não às SA não pode se basear na alegação de que aquelas incorporam conhecimento com credenciais epistêmicas superiores. Mais plausível, em nossa opinião, é o inverso: o conhecimento materialista é privilegiado (tido como detentor de maior valor social e talvez, erroneamente, maior valor epistêmico), pois na aplicação ele pode ser facilmente incorporado em produtos com valor de mercado, inclusive alguns para os quais pode-se obter as proteções dos DPIs. O prestígio dos métodos materialistas e o usual estreitamento do significado de "ciência" refletem não credenciais epistêmicas superiores, mas o maior valor social de suas aplicações entre aqueles que dão prioridade a relações de controle sobre os objetos naturais e o valor econômico das coisas. ${ }^{4}$

A concessão das proteções dos DPIs às sementes TG e a "pirataria" com as sementes SA são momentos diferentes do mesmo processo. Se a ciência não fornece uma justificativa para legitimar a atribuição de diferentes estatutos legais para os dois tipos de sementes, é possível que se recorra a outra razão: sem as proteções dos DPIs, o desenvolvimento e a utilização de sementes TG provavelmente encontraria obstáculos intransponíveis. Dentro da lógica da economia neoliberal global tal alegação pode ser muito convincente, especialmente porque a pesquisa associada à maximização bem pode dar apoio à tese de que (em estruturas neoliberais) apenas com os novos métodos é possível produzir alimentos adequadamente. Mas para conseguir legitimação além dos limites dessa lógica, é necessário apelar também para a pressuposição de que "As sementes TG são necessárias para alimentar a humanidade", para a qual, de novo, não há base científica até agora. $^{5}$

O tribunal da ciência permanece aberto às possibilidades de produzir alimento de modo que todos possam ser alimentados nas próximas décadas. A questão pode ser submetida à exploração científica mas apenas, como vimos, se reconhecermos que a ciência contém uma multiplicidade de diferentes tipos de métodos, incluindo os agroecológicos tanto quanto os materialistas. Tal exploração ainda não foi tentada e, se for, pode tornar válida a pressuposição dos defensores das sementes TG, mas também pode ser que isto não aconteça; e pode levar à conclusão de que há papéis importantes tanto para as sementes SA quando para as TG nas práticas agrícolas que não apenas produzir em quantidade suficiente para alimentar a todos, mas o fazer de modo a assegurar que todos sejam adequadamente alimentados e que respondam à questão do fortalecimento local de forma bem geral. ${ }^{6}$ Antes da exploração os críticos não fazem jus a maior certeza que os defensores.

Ao mesmo tempo, os dados empíricos atuais apóiam a afirmação que responder à maximização não é suficiente para responder ao empoderamento local; e de que em numerosas localidades em todo o terceiro mundo tentativas de tratar do fortalecimento local sistemática e resolutamente têm sido promissoras, recorrendo a métodos agroecológicos com pequena contribuição de tentativas de responder à maximização (Altieri, 1995). Uma investigação fidedigna da pressuposição de que "não há outra maneira de alimentar a humanidade" deve levar isto em conta. Ela vai requerer, portanto, que investigações com métodos agroecológicos sejam desenvolvidas muito mais completamente, e com provisão dos recursos necessários; e esses métodos podem ser desenvolvidos apenas se práticas agroecológicas são intensificadas e ampliadas. O fornecimento de tais recursos, entretanto, entra em conflito com as tendências da própria economia global, cuja lógica favorece a transformação rápida e imediata dos métodos agrícolas na direção do uso de sementes TG em larga escala. Tal tendência serve para solapar as condi- 
ções (a disponibilidade de agroecossistemas produtivos e sustentáveis) necessárias para a investigação científica de uma pressuposição daquilo que a legitima.

Qualquer autoridade que a ciência legalmente exerça deriva dos resultados de investigação empírica sistemática. Tal autoridade não apóia nem as distinções legais entre as sementes TG e SA, nem que os métodos agrícolas que usam as sementes SA não devam ter um papel integral na produção de alimento nas próximas décadas. Talvez 0 apelo à ciência feito pelos defensores das sementes TG mascare a falta de um fundamento moralmente convincente para a globalização, ou um esforço para enervar seus críticos, ou uma fé ilimitada nos poderes dos métodos materialistas. Em qualquer caso, os críticos que recorrem à agroecologia não se opõem à ciência estabelecida. Ao contrário, o fortalecimento da agroecologia é necessário para que haja uma investigação científica das possibilidades de alimentar a todos no futuro imediato $\mathrm{e}$ no futuro previsível.

No conflito sobre as sementes, dois modos de vida fundamentalmente incompatíveis se contrapõem: um enfatizando os agroecossistemas sustentáveis, o outro, a primazia do mercado. A ciência (pesquisa empírica sistemática), pela sua multiplicidade de métodos, pode informar a ambas porém não legitima nenhuma. A oposição ao desenvolvimento e à utilização de sementes TG pode se enraizar mais solidamente nas práticas da agroecologia. É aí que as energias dos críticos devem ser postas - essa é uma questão de solidariedade, prática agrícola, economia política, estilo de vida, e aquisição de conhecimento.

\section{NOTAS}

Tradução de Marcos Barbosa de Oliveira.

O presente artigo é parte de um projeto maior, apoiado em parte pela US National Science Foundation (SES-9905945), que trata de questões filosóficas, éticas e científicas referentes à agrobiotecnologia e à agroecologia.

1. Destacados porta-vozes do agribusiness, tais como Robert Shapiro, presidente-executivo da Monsanto, tendem a recomendar a rápida transformação da agricultura na direção de uma substancial dependência de culturas TG (ver as observações de Shapiro em Specter, 2000). Outros, inclusive os associados das organizações filiadas ao CGIAR (Consultive Group on International Agricultural Research), alegam mais modestamente que a sementes TG têm um papel importante a desempenhar na agricultura do futuro (Serageldin, 1999; Persey e Lantin, 2000; Nuffield Council on Bioethics, 1999; McGloughlin, 2000). O CGIAR tende a ser crítico de muitos desenvolvimentos de sementes TG realizados pelo agribusiness, considerando-os impulsionados pelo lucro, em vez de pelas necessidades de comunidades agrícolas pobres; tendo por objetivo o aumento nas vendas de pesticidas específicos ou a conquista de maior controle do mercado, em vez de aumento na produtividade de culturas especialmente em solos inferiores e alimentos saudáveis. Ironicamente, porta-vozes do agribusiness referem-se com freqüência à pesquisa patrocinada pelo CGIAR, que tem pouco potencial de lucro a curto prazo, para sustentar que o desenvolvimento de sementes TG serve a fins humanitários.
2. O caso extremo de biopirataria ocorre quando um órgão estrangeiro consegue patentes para pequenas variantes de produtos disponíveis há séculos em países "subdesenvolvidos" e que são bem compreendidos dentro de sistemas de conhecimento local - por exemplo, produtos da árvore neem na Índia (Shiva, 1997: 69 72) e o arroz basmati (Shiva, 2000: 84-86). Uma decisão judicial recente revogou a patente concedida ao Departamento de Agricultura dos Estados Unidos e a W. R. Grace Corporation para um produto de neem pela razão de que não estava envolvido passo inventivo algum (The Times of India News Service, 12 de Maio de 2000). Sobre o papel da biopirataria em certas áreas de pesquisa médica e a indústria farmacêutica, ver Alier, 2000.

3. Miguel Altieri é chileno, e atualmente professor no Departamento de Environmental Science, Policy and Management da Universidade da Califórnia Berkeley; coordenador-geral do Development Programme's Sustainable Agriculture Networking and Extension Programme da ONU; e assessor técnico do Latin American Consortium on Agroecology and Development.

4. Argumentou-se em outro lugar (Lacey, 1998, cap. 5; 1999, cap. 6) que há relações complexas mutuamente reforçadoras entre a pesquisa científica praticada quase exclusivamente de acordo com métodos materialistas e a valorização do controle sobre os objetos naturais.

5. Fora da lógica da economia neoliberal global, como sugerimos, não há base para atribuir um status (epistêmico ou legal) diferente para as sementes SA e TG. Existe, por outro lado, uma séria necessidade de os países do terceiro mundo protegerem suas reservas genéticas indígenas. Como fazer isso tem sido objeto de considerável controvérsia (Brush e Stabinsky, 1996; Alier, 2000; Lacey, 1998, cap. 6). Alguns autores sugeriram que os DPIs sejam estendidos para os recursos genéticos indígenas, outros propuseram que não sejam concedidas patentes a qualquer material vivo, incluindo sementes TG, ou várias formas de compensação pelo uso de recursos indígenas. Uma idéia promissora, que apenas recentemente começou a ser explorada, é desenvolver um enquadramento legal para "direitos intelectuais coletivos", de acordo com os quais comunidades de agricultores (e povos indígenas) possam proteger, aperfeiçoar e controlar o uso das reservas genéticas situadas no âmbito de seu conhecimento local (Shiva, 1997:80; Garcia dos Santos, 1996).

6. Pode existir bastante espaço para um debate construtivo entre a agroecologia e a pesquisa sobre sementes TG associada ao CGIAR (McGloughlin, 2000). Ambas as abordagens se propõem a ser sensíveis às necessidades e problemas dos agricultores pobres. Em vez de empoderamento local, entretanto, a pesquisa ligada ao CGIAR tende a se preocupar com uma questão ligeiramente diferente: como podem os métodos da agrobiotecnologia ser desenvolvidos de tal modo que possam contribuir para satisfazer (por exemplo) as necessidades de produção de alimentos e lidar com desnutrição crônica em comunidades de agricultores pobres. Ela pressupõe que abordagens materialistas na ciência constituem a maior parte da solução dos problemas com os quais se defrontam as comunidades pobres mas, embora reconhecendo a "realidade" do regime dos DPIs, rejeita tanto a dominância da pesquisa em biotecnologia pelo agribusiness quanto o mercado enquanto único acesso a sementes disponível para os agricultores. Assim, o CGIAR conduz pesquisas visando desenvolver sementes TG que, por exemplo, podem produzir arroz com maior teor de vitamina, ou que podem ser cultivadas em solos salinos ou secos, desta forma fornecendo soluções técnicas para importantes problemas de agricultores pobres ou marginalizados. A agroecologia, em contraste, insiste em que as soluções técnicas propostas não sejam abstraídas dos contextos ecológicos e sociais em suas implementações (Shiva, 1991).

\section{REFERÊNCIAS BIBLIOGRÁFICAS}

ALCAMO, I. E. DNA technology: the awesome skill. Dubuque (Iowa), Wm. C. Brown Publishers, 1996.

ALIER, J.M. "International biopiracy versus the value of local knowledge". Capitalism, Nature, Socialism: a Journal of Socialist Ecology, v.11, n.2, jun. 2000, p.59-68.

ALTIERI, M. Agroecologia: a dinâmica produtiva da agricultura sustentável. Rio Grande do Sul, Editora da Universidade Federal do Rio Grande do Sul, 1998.

Agroecology: the science of sustainable agriculture. $2^{\mathrm{a}}$ ed. Boulder (Colorado), Westview, 1995.

ALTIERI, M. e ROSSET, P. "Ten reasons why biotechnology will not help the developing world" and "Why biotechnology will not help the developing world". AgBioForum, v.2, 2000 (www.agbioforum.org.). 
BRUSCH, S.B. e STABINSKY, D. Valuing local knowledge: indigenous people and intellectual property rights. Washington, Island Press, 1996.

GARCIA DOS SANTOS, L. e MUZIO, G. "Collective intellectual rights and control of access to biological resources". In: TILAHUN, S. e EDWARDS, $\mathrm{S}$. (orgs.). The movement for collective intellectual rights. Adis Abeba e Londres, The Gaia Foundation, 1996.

KLOPPENBURG Jr., J. “The plant germplasm controversy”. Bioscience, v.37, 1987, p.190-198.

. First the seed: the political economy of plant biology 1492-2000. Cambridge, Cambridge University Press, 1988.

. "Social theory and the de/reconstruction of agricultural science: local knowledge for an alternative agriculture”. Rural Sociology, v.56, 1991, p.519-548.

LACEY, H. "Incommensurability and 'multicultural science'”. In: HOYNINGENHUENE, P. e SANKEY, H. (orgs.). Incommensurability and related matters. Dordrecht, Kluwer, no prelo.

. Valores e atividade científica. São Paulo, Discurso Editorial, 1998. . Is Science Value Free?: Values and scientific understanding. Londres, Routledge, 1999.

LAPPÉ, M. e BAILEY, B. Against the grain: biotechnology and the corporate takeover of your food. Monroe (Maine), Common Courage Press, 1998.

LEWONTIN, R.C. "The maturing of capitalist agriculture: farmer as proletarian". Monthly Review, v.50, n.3, 1998, p.72-84.
LEWONTIN, R.C. e BERLAN, J.-P. "The political economy of agricultural research: the case of hybrid corn". In: CARROLL, C.R.; VANDEMEER, J.H. e ROSSET, P.M. (orgs.). Agroecology. Nova York, McGraw-Hill, 1990.

McGLOUGHLIN, M. "Ten reasons why biotechnology will be important to the developing world". AgBioForum, v.2, 2000 (www.agbioforum.org.).

NUFFIELD COUNCIL ON BIOETHICS. Genetically modified crops: the social and ethical issues. London, The Nuffield Foundation, 1999.

PERSEY, G.J. e LANTIN, M.M. Agricultural biotechnology and the poor. Washington, CGIAR e US National Academy of Science, 2000.

PRÍNCIPE DE GALES (Príncipe Charles). "Seeds of disaster". The Ecologist, v.28, n.5, set./out. 1998, p.252-253.

RISLER, J. e MELLON, M. The ecological risks of engineered crops. Cambridge, MIT Press, 1996.

SERAGELDIN, I. "Biotechnology and food security in the $21^{\text {st }}$ century". Science, v.285, 16 de julho de 1999, p.387-389.

SHIVA, V. The Violence of the Green Revolution. Londres, Zed Books, 1991.

. Monocultures of the mind: perspectives on biodiversity and biotechnology. Londres, Zed Books, 1993.

Biopiracy: the plunder of nature and knowledge. Boston, South End Press, 1997.

. Stolen harvest: the hijacking of the global food supply. Boston, South End Press, 2000.

SPECTER, M. "The pharmageddon riddle". The New Yorker, 10/04/2000, p.58-71. 